\title{
Editorial: Wetland Biogeochemistry: Response to Environmental Change
}

\author{
Fereidoun Rezanezhad $^{1 *}$, Colin P. R. McCarter ${ }^{2}$ and Bernd Lennartz ${ }^{3}$ \\ ${ }^{1}$ Ecohydrology Research Group, Water Institute and Department of Earth and Environmental Sciences, University of \\ Waterloo, 200 University Avenue West, N2L 3G1, Waterloo, ON, Canada, ${ }^{2}$ Department of Physical and Environmental \\ Sciences, University of Toronto, Scarborough, ON, Canada, ${ }^{3}$ Faculty of Agricultural and Environmental Sciences, University \\ of Rostock, Justus-von-Liebig-Weg 6, 18059, Rostock, Germany
}

Keywords: wetlands, biogeochemical cycling, climate change, peatlands, hydrological processes

\section{Editorial on the Research Topic}

\section{Wetland Biogeochemistry: Response to Environmental Change}

\section{OPEN ACCESS}

Edited by:

Vera I. Slaveykova,

Université de Genève, Switzerland

Reviewed by:

Adrien Mestrot,

University of Bern, Switzerland

*Correspondence: Fereidoun Rezanezhad frezanez@uwaterloo.ca

Specialty section:

This article was submitted to Biogeochemical Dynamics, a section of the journal Frontiers in Environmental Science

Received: 08 April 2020 Accepted: 27 April 2020 Published: 29 May 2020

Citation:

Rezanezhad F, McCarter CPR and Lennartz B (2020) Editorial: Wetland Biogeochemistry: Response to

Environmental Change.

Front. Environ. Sci. 8:55.

doi: 10.3389/fenvs.2020.00055
Wetlands around the world are increasingly impacted by a shift in environmental conditions due to climate change, land use development, resource extraction, urbanization, and sea level rise, to name a few external pressures (Meng et al., 2016; Walpole and Davidson, 2018). These environmental changes can alter the hydrological regime, impacting the biogeochemical processes that govern important wetland ecosystem services, such as carbon sequestration and water storage. Biogeochemical processes in wetlands are highly dynamic (Reddy et al., 2010; Jackson et al., 2014) and involve complex interactions between hydrological processes, mineralogical transformations, bacterial and vegetation communities, and soil stores of carbon and nutrients (Cherry, 2011; U.S. EPA, 2015). Currently, our understanding of biogeochemical properties of wetlands are derived from mechanistic and statistical links between biological, geological, and chemical processes. However, how climatic and hydrological processes interact with wetland biogeochemical functions is still not well-understood.

Wetland ecosystems maintain a fragile balance between soil, water, plant, microbial, and atmospheric processes, which regulates water flow and water quality (Reddy and Delaune, 2008). Even minor gradients (naturally or anthropogenically induced) in hydrological and climatic parameters (e.g., wetting and drying, flooding, freezing, and thawing, groundwater-surface water interactions, etc.) can change the ecology and (bio)geochemistry of wetlands. These changes can have profound impacts on globally important processes, such as greenhouse gas emissions. Within a wetland, there is a high degree of spatial and temporal heterogeneity of chemical properties, temperature, and water-saturation that regulates the transport and transformation of carbon, nutrients, and redox-active elements (Reddy et al., 2010; Cherry, 2011; Jackson et al., 2014). The heterogeneity results in both spatial and temporal pulses of biogeochemical activity, primarily associated with aerobic or anaerobic microbial respiration. Thus, wetlands are considered "biogeochemical hotspots" in the landscape, with an enhanced cycling of nutrients, carbon and trace metals (Megonigal, 2008; Reddy et al., 2010; Cherry, 2011). Quantifying the variability in process intensity remains challenging but is, however, critical to unravel the linkages between forcing environmental boundary conditions and biogeochemical responses.

This Research Topic brings together wetland (bio)geochemists, hydrologists, biologists, ecologists, and soil scientists to share research in various areas of wetland biogeochemistry 
that addresses how current and future hydroclimatic conditions and land use change modulate (bio)geochemical processes in wetlands. The resultant collection of papers covers a broad snapshot of our understanding of how biogeochemical transformations and the movement of water in wetlands impacts the concentration and mobility of nutrients and contaminants, microbial community dynamics, greenhouse gas emissions, carbon cycling, and sequestration. The studies cover a range of freshwater wetland classifications (i.e., marsh, peatland, etc.) in natural, disturbed, and restored environments. The assembled papers provide important new information that addresses critical knowledge gaps on how wetland biogeochemistry is impacted by environmental change.

The impact of environmental change on vegetation and subsequent impacts on biogeochemical cycling are apparent and several papers in this Research Topic showcase the interconnected nature of wetland biogeochemistry, ecology, and carbon cycling. Yuckin and Rooney quantified the effect of Phragmites australis invasion on carbon and macronutrient standing stocks in a freshwater coastal marsh, highlighting that plant invasions may create trade-offs between ecosystem processes. Yavitt et al. examined the importance of leaf litter in carbon cycling in peatlands and why vegetation, plant species composition, and peatland type must be determined to put peatland ecosystems into the context of global carbon budgets. Turner et al. demonstrated how wind sheltering influences land-atmosphere fluxes of carbon in wetlands and plays an important role on wetland ecosystem characteristics and energy balance. Koop-Jakobsen and Gutbrod observed distinctive spatio-temporal oxygen dynamics in an open tidal marsh that differs from the surrounding shaded vegetated marsh. The authors highlight the role of vascular plant canopies for biogeochemical processes in wetlands. It is evident from these papers that the feedbacks between vegetation and biogeochemical processes in wetlands provide an important mechanism that regulates essential ecosystem services.

Several authors highlighted the complex controls and interactions between microbiological communities, biogeochemical processes, and hydrological setting. In coastal peatlands, Gosch et al. assessed the change in the decomposition of organic matter and releasing organic and inorganic solutes from peat under seawater intrusion. While in inland peatlands, Negassa et al. discussed the lack of empirical data on the high variability of chemical and biochemical properties in rewetted peatlands. Zak et al. examined if long-term peat mineralization during decades of drainage in minerotrophic fens causes an enrichment or a decline of enzyme-inhibiting polyphenols.

\section{REFERENCES}

Cherry, J. A. (2011). Ecology of wetland ecosystems: water, substrate, and life. Nat. Educ. Knowl. 3:16.

Jackson, C. R., Thompson, J. A., and Kolka, R. K. (2014). "Wetland soils, hydrology and geomorphology, Chapter 2," in Ecology of Freshwater and Estuarine Wetlands, eds D. Batzer and R. Sharitz (Berkeley: University of California Press), 23-60.
While, Alshehri et al. evaluated the potential of adding phenolic compounds to peatland soils to inhibit extracellular enzyme activities in order to reduce the flux of $\mathrm{CO}_{2}$ from peatlands; the authors recommend phenolic enrichment as a potential peatland restoration strategy. Limpert et al. examined the $\mathrm{CO}_{2}$ and $\mathrm{CH}_{4}$ emissions and microbial community diversity during a wetland rehabilitation process (rewetting) and observed a clear succession of microbial communities during the dry-wet phases, suggesting that wetland hydrology plays a significant role in the microbial community structure. All of the publications in this Research Topic elucidate strong linkages between the hydrophysical setting and biogeochemical processes and recognized that understanding the feedbacks associated with these linkages requires further studies.

With 42 authors from six countries in Europe, North America, and Australia/Oceania this Research Topic identifies key priorities for future research in wetlands biogeochemical transformation and processes. This Research Topic highlights the need for a more detailed understanding of interactions between and cycling of carbon, oxygen, nitrogen, phosphorus, and sulfur. The authors emphasize the role of redox- $\mathrm{pH}$ conditions, organic matter, microbial-mediated processes that drive nutrient and carbon transformations in wetlands, plant responses, and adaptation to wetland soil conditions. Importantly, the contributions emphasize the need for more integrated research efforts into the physical, hydrological and climatic processes that regulate wetland biogeochemical processes. The further development of interdisciplinary linkages is considered essential for a process-based understanding of wetland functions and the successful restoration and management of wetland ecosystems.

\section{AUTHOR CONTRIBUTIONS}

All authors listed have made a substantial, direct and intellectual contribution to the work, and approved it for publication.

\section{ACKNOWLEDGMENTS}

FR acknowledged funding supports from the Canada Excellence Research Chair program in Ecohydrology and the Global Water Futures funded by the Canada First Excellence Research Fund. CM acknowledged funding provided by the Natural Sciences and Engineering Research Council of Canada Postdoctoral Fellowship. BL is grateful for the support by the Research Training Group Baltic TRANSCOAST program, funded by the DFG under grant number DFG-GRK 2000/1, and the WETSCAPES project (ESF/14-BM-A55-0028/16). 
submitted to U. S. Environmental Protection Agency. EPA Contract No. EP-C09-001.

Reddy, K. R., and Delaune, R. D. (2008). Biogeochemistry of Wetlands: Science and Applications. Boca Raton, FL: CRC Press.

U.S. EPA. (2015). Connectivity Of Streams And Wetlands To Downstream Waters: A Review And Synthesis Of The Scientific Evidence (Final Report). (Washington, DC: U.S. Environmental Protection Agency), EPA/600/ R-14/475F.

Walpole, M., and Davidson, N. (2018). Stop draining the swamp: it's time to tackle wetland loss. Oryx 52, 595-596.
Conflict of Interest: The authors declare that the research was conducted in the absence of any commercial or financial relationships that could be construed as a potential conflict of interest.

Copyright (๑) 2020 Rezanezhad, McCarter and Lennartz. This is an open-access article distributed under the terms of the Creative Commons Attribution License (CC $B Y)$. The use, distribution or reproduction in other forums is permitted, provided the original author(s) and the copyright owner(s) are credited and that the original publication in this journal is cited, in accordance with accepted academic practice. No use, distribution or reproduction is permitted which does not comply with these terms. 